\title{
Chest computed tomography for the diagnosis of patients with coronavirus disease 2019 (COVID-19): a rapid review and meta-analysis
}

\author{
Meng Lv ${ }^{1,2 \#}$, Mengshu Wang ${ }^{3 \#}$, Nan Yang ${ }^{4,5,6}$, Xufei Luo ${ }^{1,2}$, Wei $\mathrm{Li}^{5,6,7}$, Xin Chen ${ }^{5,6,7}$, Yunlan Liu ${ }^{1}$, Mengjuan \\ Ren $^{1}$, Xianzhuo Zhang ${ }^{8}$, Ling Wang ${ }^{1}$, Yanfang Ma $^{2}$, Junqiang Lei ${ }^{3}$, Toshio Fukuoka ${ }^{9,10}$, Hyeong Sik \\ $\mathrm{Ahn}^{11,12}$, Myeong Soo Lee ${ }^{13,14}$, Zhengxiu Luo ${ }^{4,5,6}$, Yaolong Chen ${ }^{2,15,16,17}$, Enmei Liu ${ }^{4,5,6}$, Jinhui Tian ${ }^{2,17}$, Xiaohui \\ Wang $^{1}$; on behalf of COVID-19 Evidence And Recommendations Working Group
}

${ }^{1}$ School of Public Health, Lanzhou University, Lanzhou 730000, China; ${ }^{2}$ Evidence-based Medicine Center, School of Basic Medical Sciences, Lanzhou University, Lanzhou 730000, China; ${ }^{3}$ Department of Radiology, The First Affiliated Hospital, Lanzhou University, Lanzhou 730000 , China; ${ }^{4}$ Department of Respiratory Medicine, Children's Hospital of Chongqing Medical University, Chongqing 400014, China; ${ }^{5}$ National Clinical Research Center for Child Health and Disorders, Ministry of Education Key Laboratory of Child Development and Disorders, China International Science and Technology Cooperation Base of Child Development and Critical Disorders, Children's Hospital of Chongqing Medical University, Chongqing 400014, China; ${ }^{6}$ Chongqing Key Laboratory of Pediatrics, Chongqing 400014, China; ${ }^{7}$ Department of Radiology, Children's Hospital of Chongqing Medical University, Chongqing 400014, China; ${ }^{8}$ The First School of Clinical Medicine, Lanzhou University, Lanzhou 730000 , China; ${ }^{9}$ Emergency and Critical Care Center, the Department of General Medicine, Department of Research and Medical Education at Kurashiki Central Hospital, Kurashiki, Japan; ${ }^{10}$ Advisory Committee in Cochrane Japan, Tokyo, Japan; ${ }^{11}$ Department of Preventive Medicine, Korea University College of Medicine, Seoul, Korea; ${ }^{12}$ Korea Cochrane Centre, Seoul, Korea; ${ }^{13}$ Korea Institute of Oriental Medicine, Daejeon, Korea; ${ }^{14}$ University of Science and Technology, Daejeon, Korea; ${ }^{15}$ Lanzhou University, an Affiliate of the Cochrane China Network, Lanzhou 730000, China; ${ }^{16}$ Chinese GRADE Center, Lanzhou 730000, China; ${ }^{17}$ Key Laboratory of Evidence Based Medicine and Knowledge Translation of Gansu Province, Lanzhou University, Lanzhou 730000, China

Contributions: (I) Conception and design: Y Chen, X Wang, J Tian; (II) Administrative support: J Tian, X Wang; (III) Provision of study materials or patients: M Lv, M Wang; (IV) Collection and assembly of data: N Yang, X Luo, W Li, X Chen, Y Liu, M Ren, X Zhang, L Wang; (V) Data analysis and interpretation: M Lv, M Wang, Y Ma; (VI) Manuscript writing: All authors; (VII) Final approval of manuscript: All authors.

"These authors contributed equally to this work.

Correspondence to: Jinhui Tian. Evidence-based Medicine Center, School of Basic Medical Sciences, Lanzhou University, Lanzhou 730000 , China. Email: tianjh@lzu.edu.cn; Xiaohui Wang. School of Public Health, Lanzhou University, Lanzhou 730000, China. Email: wangxiaohui@lzu.edu.cn.

Background: The outbreak of the coronavirus disease 2019 (COVID-19) has had a massive impact on the whole world. Computed tomography (CT) has been widely used in the diagnosis of this novel pneumonia. This study aims to understand the role of CT for the diagnosis and the main imaging manifestations of patients with COVID-19.

Methods: We conducted a rapid review and meta-analysis on studies about the use of chest CT for the diagnosis of COVID-19. We comprehensively searched databases and preprint servers on chest CT for patients with COVID-19 between 1 January 2020 and 31 March 2020. The primary outcome was the sensitivity of chest CT imaging. We also conducted subgroup analyses and evaluated the quality of evidence using the Grading of Recommendations Assessment, Development and Evaluation (GRADE) approach.

Results: A total of 103 studies with 5,673 patients were included. Using reverse transcription polymerase chain reaction (RT-PCR) results as reference, a meta-analysis based on 64 studies estimated the sensitivity of chest CT imaging in COVID-19 was 99\% (95\% CI, 0.97-1.00). If case reports were excluded, the sensitivity in case series was $96 \%$ (95\% CI, 0.93-0.99). The sensitivity of CT scan in confirmed patients under 18 years old was only $66 \%$ (95\% CI, $0.15-1.00$ ). The most common imaging manifestation was ground-glass opacities (GGO) which was found in 75\% (95\% CI, 0.68-0.82) of the patients. The pooled probability of bilateral involvement was $84 \%$ (95\% CI, 0.81-0.88). The most commonly involved lobes were the right lower lobe (84\%, 95\% CI, 0.78-0.90) and left lower lobe (81\%, 95\% CI, 0.74-0.87). The quality of evidence was low 
across all outcomes.

Conclusions: In conclusion, this meta-analysis indicated that chest CT scan had a high sensitivity in diagnosis of patients with COVID-19. Therefore, CT can potentially be used to assist in the diagnosis of COVID-19.

Keywords: Chest computed tomography (chest CT); Coronavirus Disease 2019 (COVID-19); meta-analysis; rapid review; sensitivity

Submitted Apr 14, 2020. Accepted for publication Apr 30, 2020.

doi: 10.21037/atm-20-3311

View this article at: http://dx.doi.org/10.21037/atm-20-3311

\section{Introduction}

In early January 2020, a disease caused by a novel coronavirus rapidly spread and across the whole world. The disease was later named as coronavirus disease 2019 (COVID-19). On 11 March 2020, COVID-19 was declared by the World Health Organization (WHO) a pandemic (1). As of 12 April 2020 , the WHO has reported 1,614,951 confirmed cases across more than 200 countries (2).

COVID-19 is a respiratory illness that can spread from human to human. Patients with the disease have mild to severe respiratory illness with symptoms such as fever, cough, dyspnea, as well as other non-specific symptoms including, fatigue, myalgia, and headache (3-5). Based on current knowledge, the median basic reproductive number $\left(\mathrm{R}_{0}\right)$ value of COVID-19 is 5.7 [95\% confidence interval (CI), 3.8-8.9] (6), which means that COVID-19 is highly contagious.

COVID-19 is mainly diagnosed by viral nucleic acid test, immunological detection, and radiological examination. However, the sensitivity of the nucleic acid test may be as low as $50 \%$ (7), and some diagnoses may be missed. As a respiratory disease, imaging detection plays an important role in the diagnosis of COVID-19. On one hand, when COVID-19 cannot be diagnosed by nucleic acid, computed tomography (CT) can be used as an auxiliary diagnostic method; on the other hand, CT can show lesions and also plays an important role in patient follow-up. Since February 2020, several case-control studies $(8,9)$, case series $(10,11)$, and case-report $(12,13)$ of CT diagnosis of COVID-19 have been published. However, there is no systematic review and meta-analysis to find out the performance of chest $\mathrm{CT}$ in the diagnosis of COVID-19. We therefore conducted this study to estimate the sensitivity of chest CT and the probability of imaging findings in cases with COVID-19 to guide the diagnosis of COVID-19. We present the following article in accordance with the PRISMA reporting checklist (available at http://dx.doi.org/10.21037/atm-20-3311).

\section{Methods}

\section{Search strategy}

We searched Medline (via PubMed), Embase, Cochrane library, Web of Science, China Biology Medicine disc (CBM), China National Knowledge Infrastructure (CNKI) and Wanfang Data between 1 January 2020 and 31 March 2020, using terms with ("2019-novel coronavirus" OR "Novel CoV" OR "2019-nCoV" OR "2019-CoV" OR COVID-19 OR SARS-CoV-2 OR "novel coronavirus pneumonia") AND ("computed tomography" OR "radiograph"” OR imagin*). The details of the search strategy can be found in the Supplementary material 1 . We also searched Google Scholar and the preprint servers, including SSRN (https://www.ssrn.com/index.cfm/en/), medRxiv (https://www.medrxiv.org/) and bioRxiv (https:// www.biorxiv.org/), as well as reference lists of the identified articles, to find additional studies. This systematic review and meta-analysis followed the PRISMA statements checklist (14).

\section{Inclusion and exclusion criteria}

In this study, we included records that focused on chest CT imaging for patients with COVID-19 published or posted in English or Chinese. We included original studies fulfilling the following criteria: (I) the study topic is related to chest CT manifestations during COVID-19 diagnosis, (II) the participants are children or adults who had an eventual confirmed diagnosis of COVID-19 by reverse transcription polymerase chain reaction (RT-PCR) testing, and (III) study design is case series and case report. We excluded studies with insufficient data and no response from the author, and studies for which we could not access the full text. 


\section{Selection of studies}

Two trained researchers ( $M$ Lv and M Wang) screened titles, abstracts, and the full texts of the identified studies independently using Endnote X9 software. Discrepancies were resolved through consultation with a third researcher. We first conducted a pretest with a small sample before the full screening, followed by discussion, to improve the consistency between the reviewers. All reasons for excluding ineligible studies were documented, and the study selection process was documented using a PRISMA flow chart.

\section{Data extraction}

Eight researchers (N Yang, X Luo, W Li, X Chen, Y Liu, M Ren, $X$ Zhang and $L$ Wang) were divided into four groups to extract the data and collect the following information for each study: basic information (title, first author, country or region of participants, date of publication/posting and study type), patient information (sample size, female/male ratio, adult/children ratio, age range, mean age), outcome information (primary outcome: sensitivity of chest CT imaging using RT-PCR results as reference; other outcomes, including probability of bilateral or unilateral pneumonia, ground-glass opacities (GGO) and consolidation, number of lobes affected, location of lobe involvement, rounded morphology, linear opacities, crazy-paving pattern, air bronchogram, interlobular septum thickening, pleural thickening, halo sign, reverse halo sign, pleural effusion and lymphadenopathy).

\section{Risk of bias assessment}

Two researchers assessed the methodological quality of case series and case reports using the revised checklist form of Murad et al. (15). The Murad et al. checklist contains a total of eight items, grouped into four domains (selection, ascertainment, causality and reporting). A pretest was performed before the formal assessment to ensure that the reviewers understood the criteria and process of evaluation consistently. Disagreements were solved by discussion or consultation with a third researcher.

\section{Data synthesis}

We performed a meta-analysis using STATA 15.1. We present data from eligible studies in an evidence table and using descriptive statistics. The percentages of the sensitivity of CT examination and the probability of imaging manifestations in patients with COVID-19 were computed using the metaprop command (Stata) for the metaanalysis of proportions. metaprop allows the inclusion of studies with proportions equal to 0 or $100 \%$ and avoids CIs surpassing the 0 to 1 range, where normal approximation procedures often break down. It achieves this by using the binomial distribution to model within-study variability or by allowing Freeman-Tukey double arcsine transformation to stabilize the variances.

We generated forest plots to show the individual and pooled probabilities of positive initial CT examination, their $95 \% \mathrm{CI}$ and study weights. We conducted subgroup analyses based on case series, and children ( $\leq 18$ years).

\section{Quality of the evidence assessment}

The quality of evidence for each outcome was assessed using the Grading of Recommendations Assessment, Development and Evaluation (GRADE) approach $(16,17)$. The criteria mainly considered included study methodological quality, directness of the evidence, heterogeneity of data, precision of effect estimates, and risk of publication bias (18-22). The quality of evidence for each outcome was graded as high, moderate, low, or very low.

As COVID-19 is a public health emergency of international concern and the situation is evolving rapidly, our study was not registered in order to speed up the process.

\section{Results}

\section{Study selection and characteristics}

The literature search retrieved 545 records. After the removal of 442 studies not meeting the inclusion criteria, 103 studies with a total of 5,673 participants were eligible for inclusion (Figure 1) (list of included studies see Supplementary material 2). The studies were published between 4 February 2020 and 31 March 2020.

\section{Study characteristics and risk of bias}

Of the 103 included studies, 82 were case series and 21 were case reports. Ninety-five studies included cases from China, and one each from Germany, Korea, Italy and the cruise ship "Diamond Princess". The characteristics of included studies were summarized in Table S1. In 53 of the 103 case 


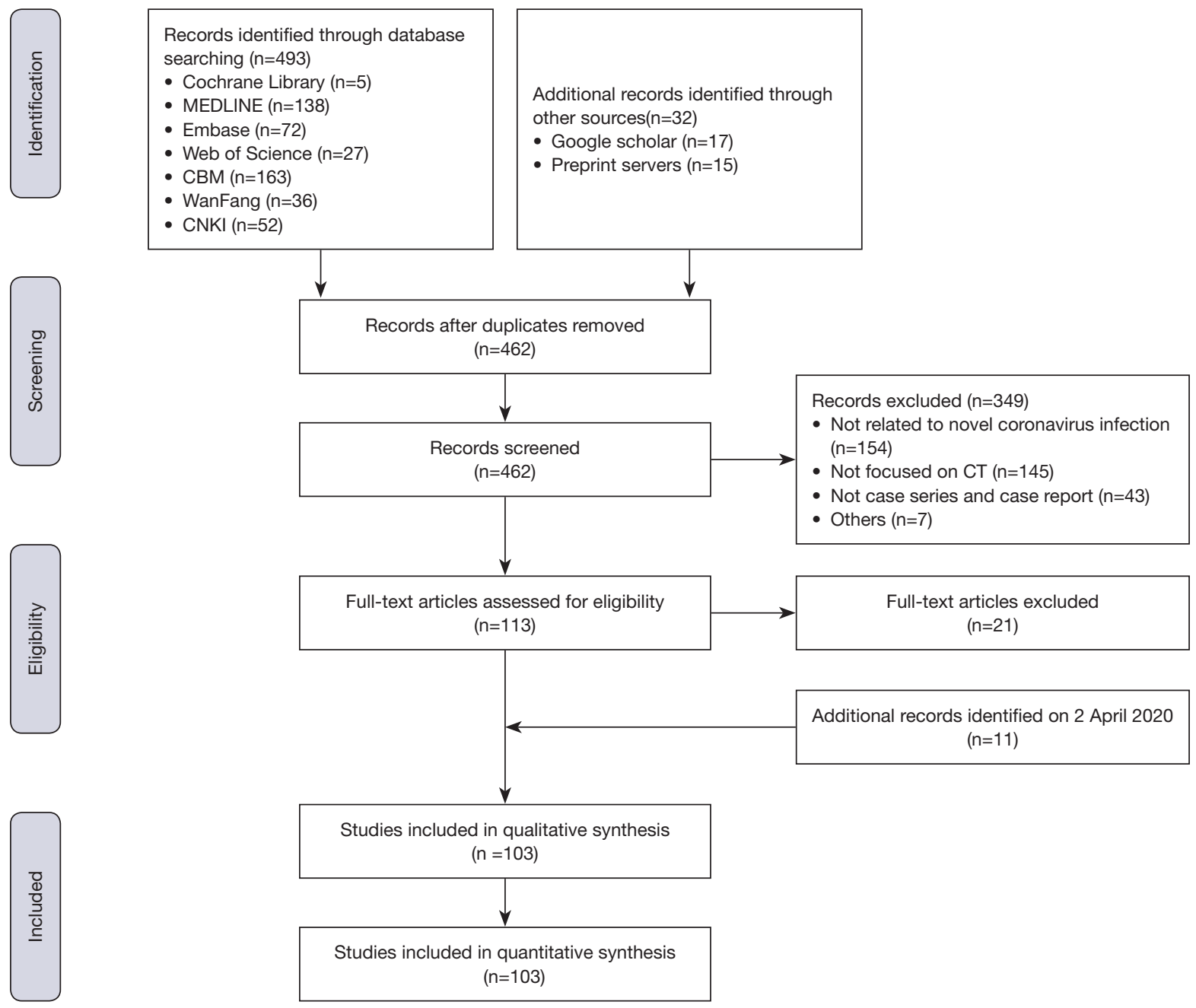

Figure 1 Flowchart of study selection process and results.

series and case reports the overall score was below 50\%, indicating a high risk of bias (see Table S2).

\section{Performance of chest CT in diagnosing COVID-19}

The result of meta-analysis showed that using RT-PCR results as reference, the pooled sensitivity of chest CT imaging of 64 studies with 3,243 COVID-19 patients was $99 \%$ (95\% CI, $0.97-1.00, \mathrm{I}^{2}=85.00 \%$ ) (Figure 2). The quality of evidence was low.

\section{Subgroup analyses}

In a subgroup analysis of 47 case series (excluding the case reports) the sensitivity of chest CT imaging was $96 \%$ (95\%
CI, $0.93-0.99, \mathrm{I}^{2}=88.70 \%$ ) (Figure $3 A$ ). The subgroup analysis of sensitivity of chest CT imaging in children based on seven studies was $66 \%$ (95\% CI, $0.15-1.00, \mathrm{I}^{2}=96.74 \%$ ) (Figure 3B). The quality of evidence was low.

\section{Probability of unilateral/bilateral involvement}

Fifty-six studies reported the probability of unilateral involvement. Our meta-analysis showed that the pooled probability of unilateral involvement was $18 \%$ (95\% CI, $0.13-0.22, \mathrm{I}^{2}=77.88 \%$ ) (Figure $4 A$ ). Sixty-seven studies reported the probability of bilateral involvement, and the pooled probability was $84 \%$ (95\% CI, 0.81-0.88, $\mathrm{I}^{2}=72.35 \%$ ) (Figure $4 B$ ). The quality of evidence for both outcomes was low. 


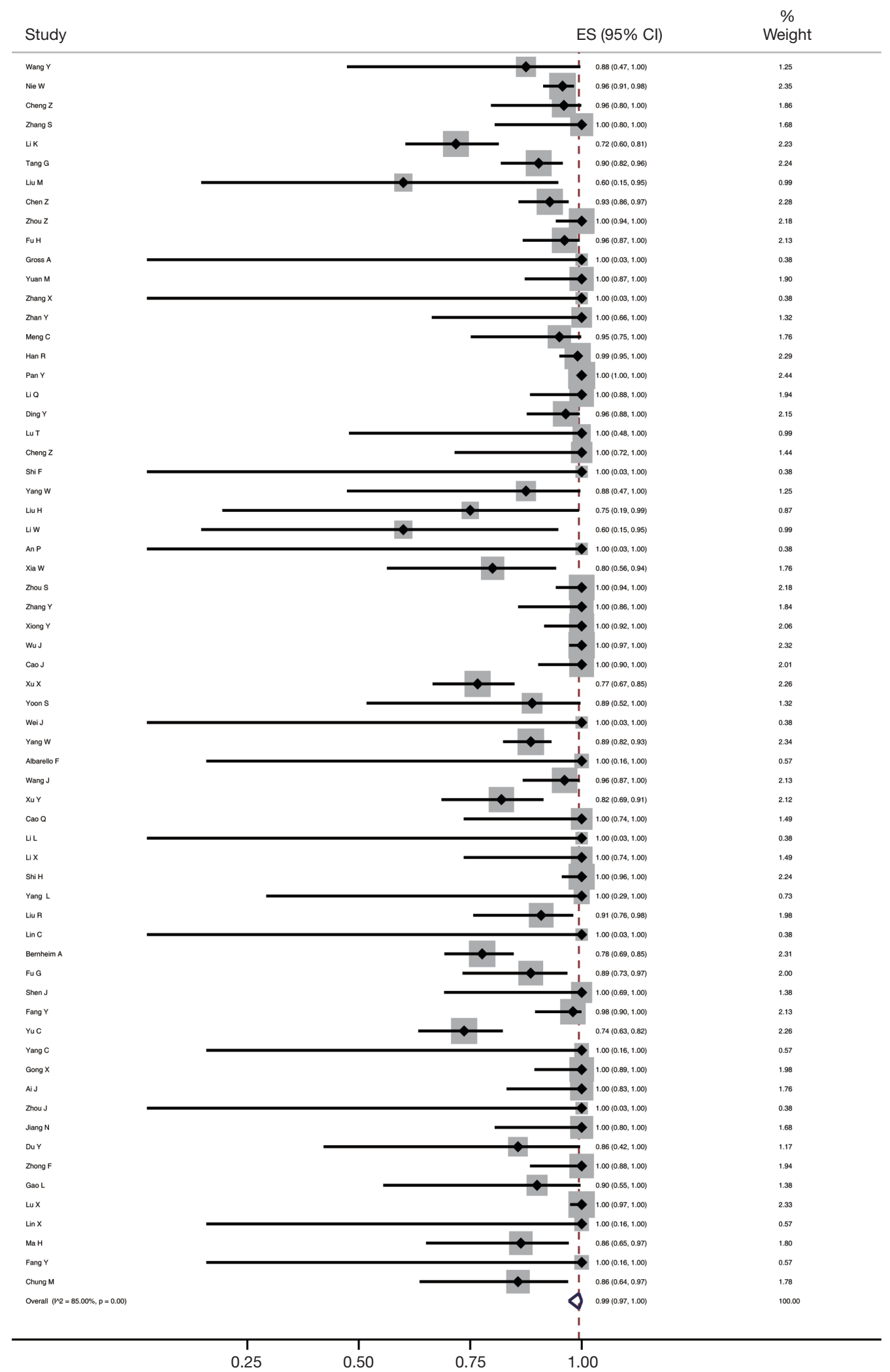

Figure 2 Meta-analysis of the sensitivity of chest CT scan in COVID-19. CT, computed tomography. 
A

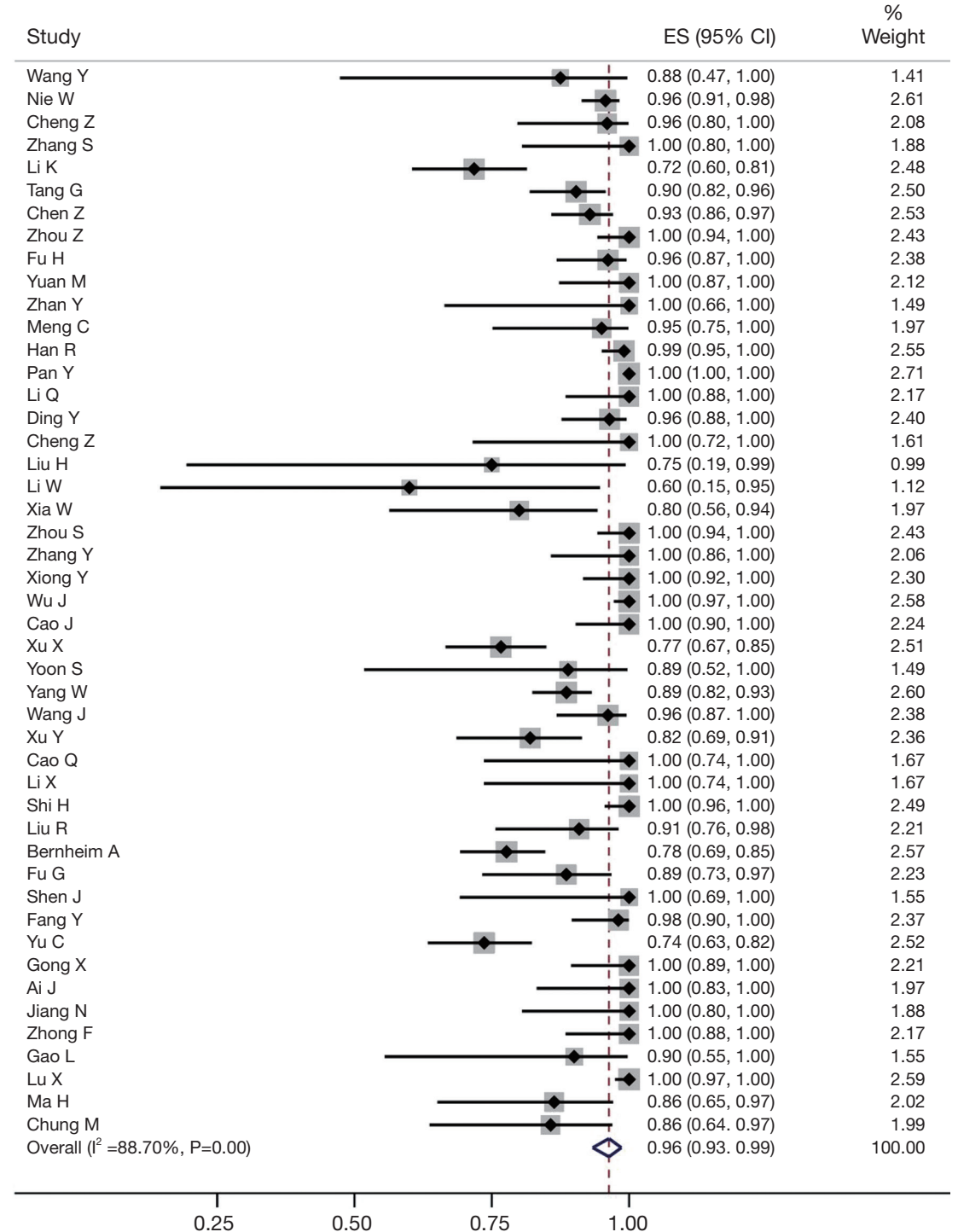

B

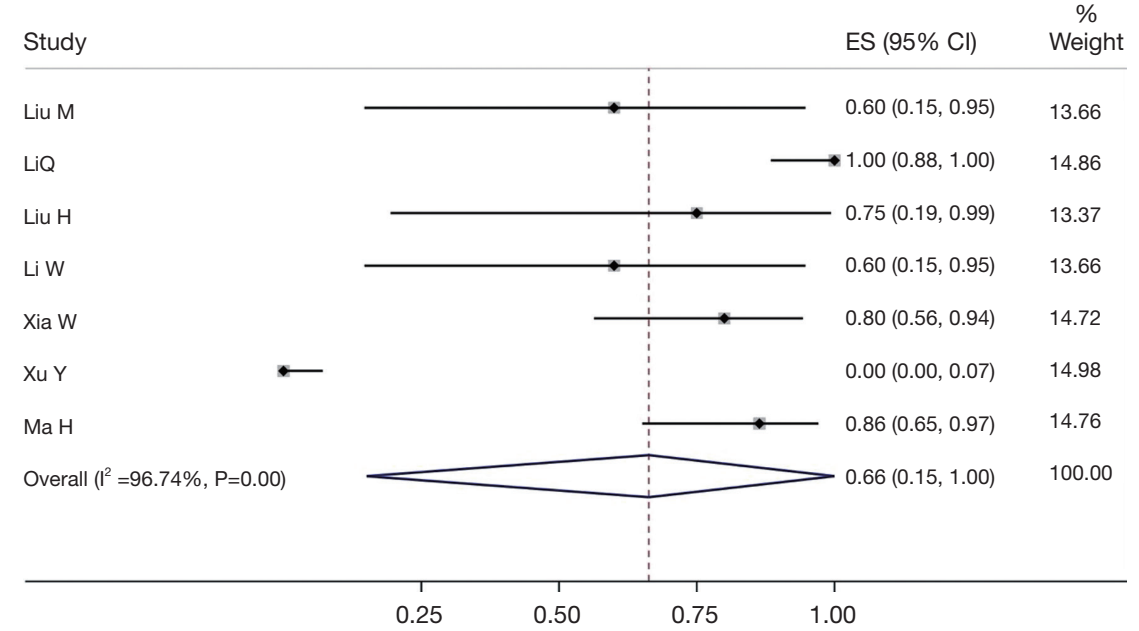

Figure 3 Subgroup analyses of the sensitivity of chest CT scan: case series (A); and children (B). CT, computed tomography; ES, estimated size. 
A study

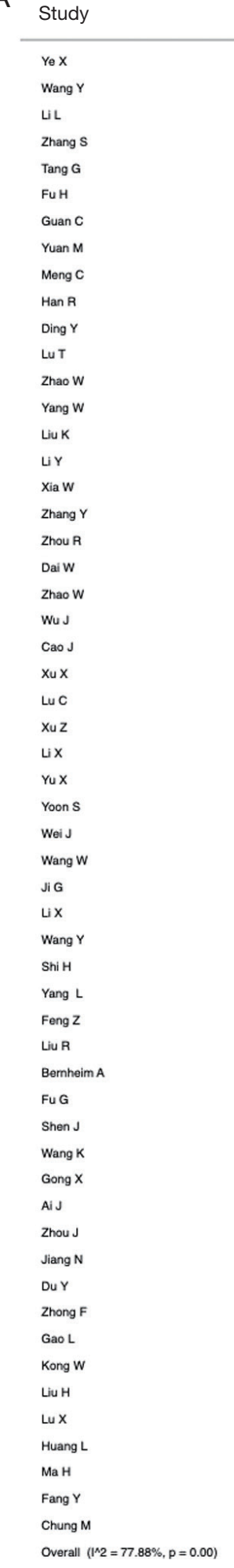

ES $(95 \%$ Cl)

$0.270 .13,0.460$
0.140 .00 .0 .58

$0.040 .000,0.20$

$0.18(0.04,0.49$
0.070 .020 .19

$0.18(0.09,0.031)$

$0.150 .04,0.039$

$0.02(0.00 .0 .007$

$0.05(0.01,0.15$

$0.15(0.09 .02020$

$0.21(0.13,0.033)$

$0.43(0.10,0.82$

(1)

1.000 .0 .03 .1 .00
$0.75(0.19 .0 .09$

0.110 los. 0.19

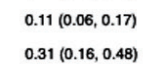

$0.41(1031,052$

$0.18(0.10,0.020$

0.070 .020 .0 .18

0.1110 .000 .040 .00

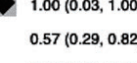

$0.27(0.15,0.42)$
$0.17(0.022 .0 .48)$

$0.43(0.5,0.51)$

$0.21(0.13,0.37)$

0.130 .080 .0 .19

$0.03(0.00,0.017$
$0.21(10.14,0.31$

$0.06(0.01,0.21)$

0.2010 .030 .0 .50
$0.11(0.02 .02020$

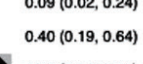

$1.00(0.03,1.00)$
$0.53(028,0.77$

$0.290 .04,0.71$

$0.3000 .15,0.498$

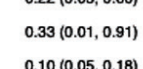

0.0250 .0 .18 .0393

$0.17(0.10,025$

$0.37(0.16,0.06$
0.50
$0.01,1,0.090$

$0.0 .110 .01,0.035$

1.00 weight

20

1.07
1.66
2.63

2.43
2.27
2.24

1.73
2.53

2.32
0.87
2.54

0.98
2.40
1.07

1.62
1.98
0.31
0.76

2.49
2.58
2.11

2.11
2.48
2.49
1.66

2.31
2.17
1.23

1.23
0.31
1.53
2.22

1.42
2.62
2.45

2.45
0.63
2.59
2.01

2.01
2.50
2.03

2.30
1.97
2.06
2.06

1.77
0.31
1.66

1.07
2.01
1.23

1.23
0.03
2.53

2.52
1.73
0.48
1.70
10000
B stod

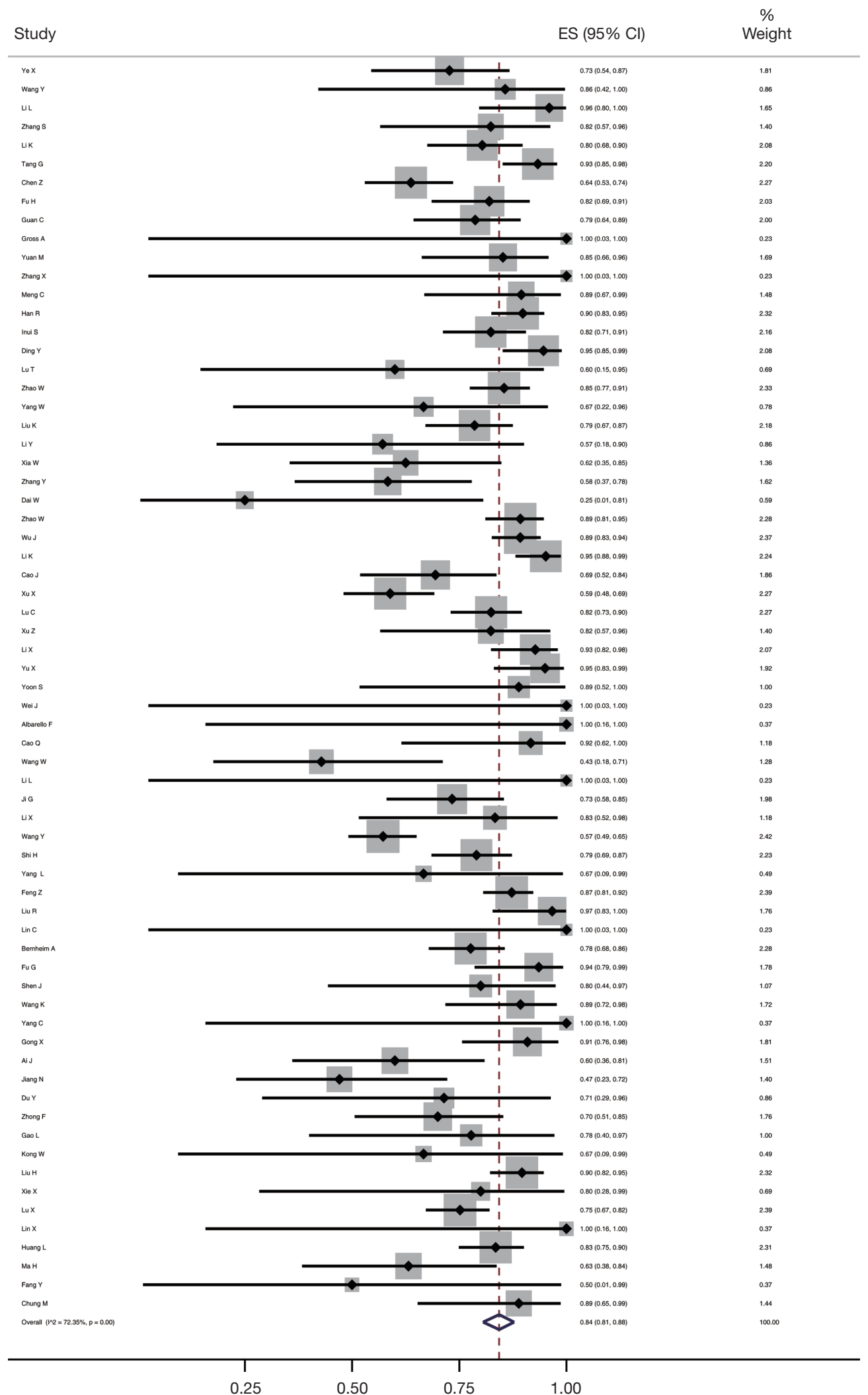

Figure 4 Meta-analyses of the probability of unilateral (A) and bilateral (B) involvement. 


\section{Probability of lesion density}

Seventy-five studies reported the proportion of the patients with GGO. The meta-analysis showed that the probability of GGO was $75 \%$ (95\% CI, 0.68-0.82, I $\left.\mathrm{I}^{2}=94.32 \%\right)$ (Figure $5 A$ ). The pooled probability of consolidation, based on a meta-analysis of 42 studies, was 34\% (95\% CI, $0.23-0.45, \mathrm{I}^{2}=95.80 \%$ ) (Figure $5 B$ ). Fifty studies reported the probability of GGO with consolidation, which was estimated $48 \%$ (95\% CI, $0.40-0.56, \mathrm{I}^{2}=88.98 \%$ ) in the meta-analysis (Figure 5C). The quality of evidence for all three outcomes was low.

\section{Secondary outcomes}

We conducted meta-analyses on the numbers of lobes affected, locations of lobes involved, and a total of 10 other secondary outcomes (Table 1). The quality of evidence for all secondary outcomes was low.

\section{Discussion}

The sensitivity of chest CT imaging in patients with COVID-19 was 99\% using RT-PCR results as reference. Therefore, CT scan can be useful in the diagnosis for people with COVID-19. However, the sensitivity of CT in children was $66 \%$, which is much lower than it in general population. The most common imaging manifestation of patients infected with SARS-CoV-2 was GGO with bilateral peripheral distribution. The quality of evidence for almost all findings in our study was low.

Viral nucleic acid detection using RT-PCR is the gold standard in the diagnosis of COVID-19. However, some studies $(23,24)$ reported that some patients had negative RT-PCR results, while their CT imaging features were abnormal. Several studies $(25,26)$ have compared the diagnostic accuracy of chest CT scan and RT-PCR and found that the sensitivity of CT was higher than that of RT-PCR. A case series (25) with 1,014 patients indicated that the sensitivity of chest CT scan for COVID-19 was $97 \%$. Our study results also showed that the sensitivity of chest CT was $99 \%$, which indicates that chest CT scan can effectively capture lung lesions in the early stage, especially in the epidemic areas. However, it is noteworthy that a small part of patients had normal CT imaging. Another systematic review (27) with 356 patients with COVID-19 also showed that $11.5 \%$ patients were diagnosed, while their CT imaging were normal, which revealed that CT examination cannot alone reliably fully exclude the diagnosis of COVID-19, notably in the early stage of infection.

Our meta-analysis showed that the most common type of imaging manifestation of patients with COVID-19 was GGO with bilateral peripheral distribution. This is consistent with a review (27), which also showed that the main imaging features in COVID-19 is GGO. The most commonly involved lobe was the right lower lobe, followed by the left lower lobe. Among the other signs, interlobular septum thickening was the most common, followed by rounded morphology and air bronchogram. Reverse halo sign, pleural effusion and lymphadenopathy were also rare. Although the sensitivity of CT scan is high, the specificity of CT in COVID-19 is limited, which need for differential diagnosis with other types of viral pneumonia (28).

Among the included studies, nine described the CT imaging features of children. The result indicated that COVID-19 tends to be mild in most children and the sensitivity of chest CT in children was only $66 \%$. The role of CT in the diagnosis of COVID-19 in children is therefore limited. Some other studies $(29,30)$ also indicated that most child patients had mild symptoms with atypical imaging findings. There is also so far no evidence to explicitly support the role of CT scan for the diagnosis of children with COVID-19. Considering that most children present only mild disease and the other risks in the process of using CT, such as radiation $(31,32)$ and hospital-based transmission (5), it is necessary to balance the advantages and disadvantages of CT use in the process of diagnosis in children with COVID-19.

Our review has several strengths. We performed a comprehensive search including databases and preprint servers and conducted meta-analyses on all main outcomes. The results of our study can thus help to better understand the role of CT imaging and the main CT manifestations in patients with COVID-19. However, this review also has some limitations: (I) though we conducted a systematic search, we only included articles published or posted in English and Chinese, which may introduce publication bias; (II) we only included case series and case reports, cases selection of included studies may introduce bias; (III) due to most of studies conducted in China, some cases may be overlapping between studies; and (IV) there was large heterogeneity between included studies.

\section{Conclusions}

In conclusion, this rapid review and meta-analysis indicates 
Annals of Translational Medicine, Vol 8, No 10 May 2020

A $_{\text {Study }}$

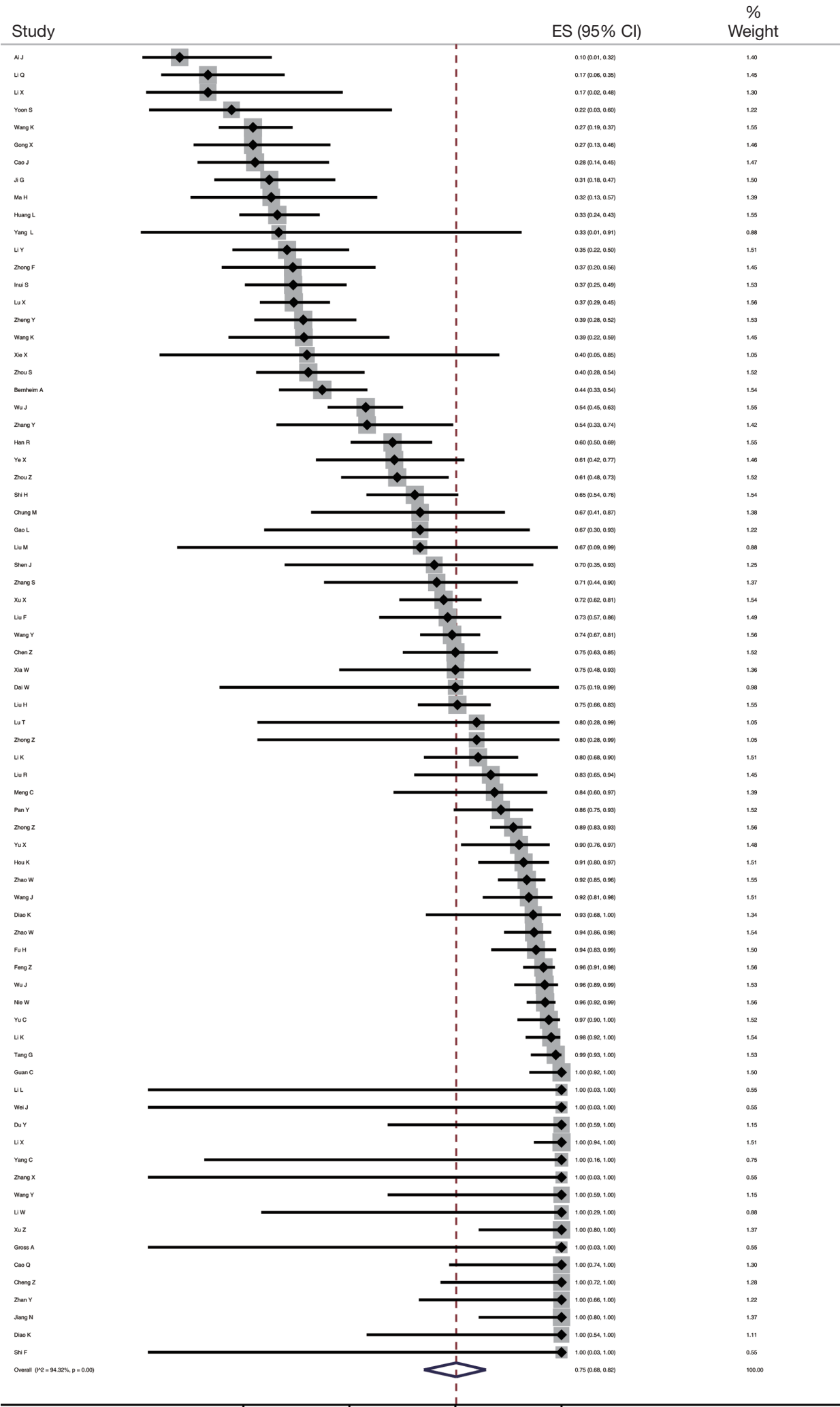

$B_{\text {Study }}$

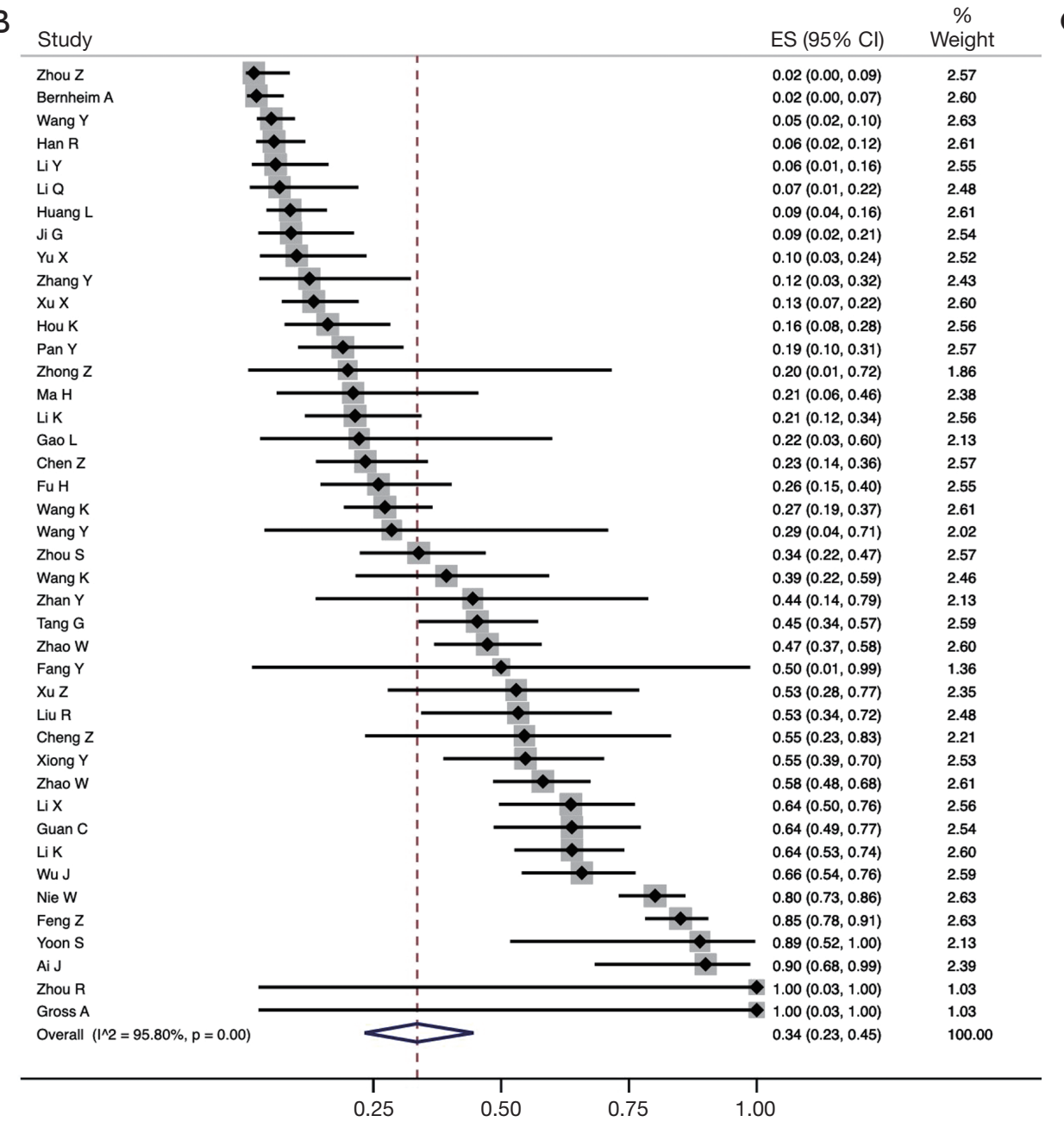

C

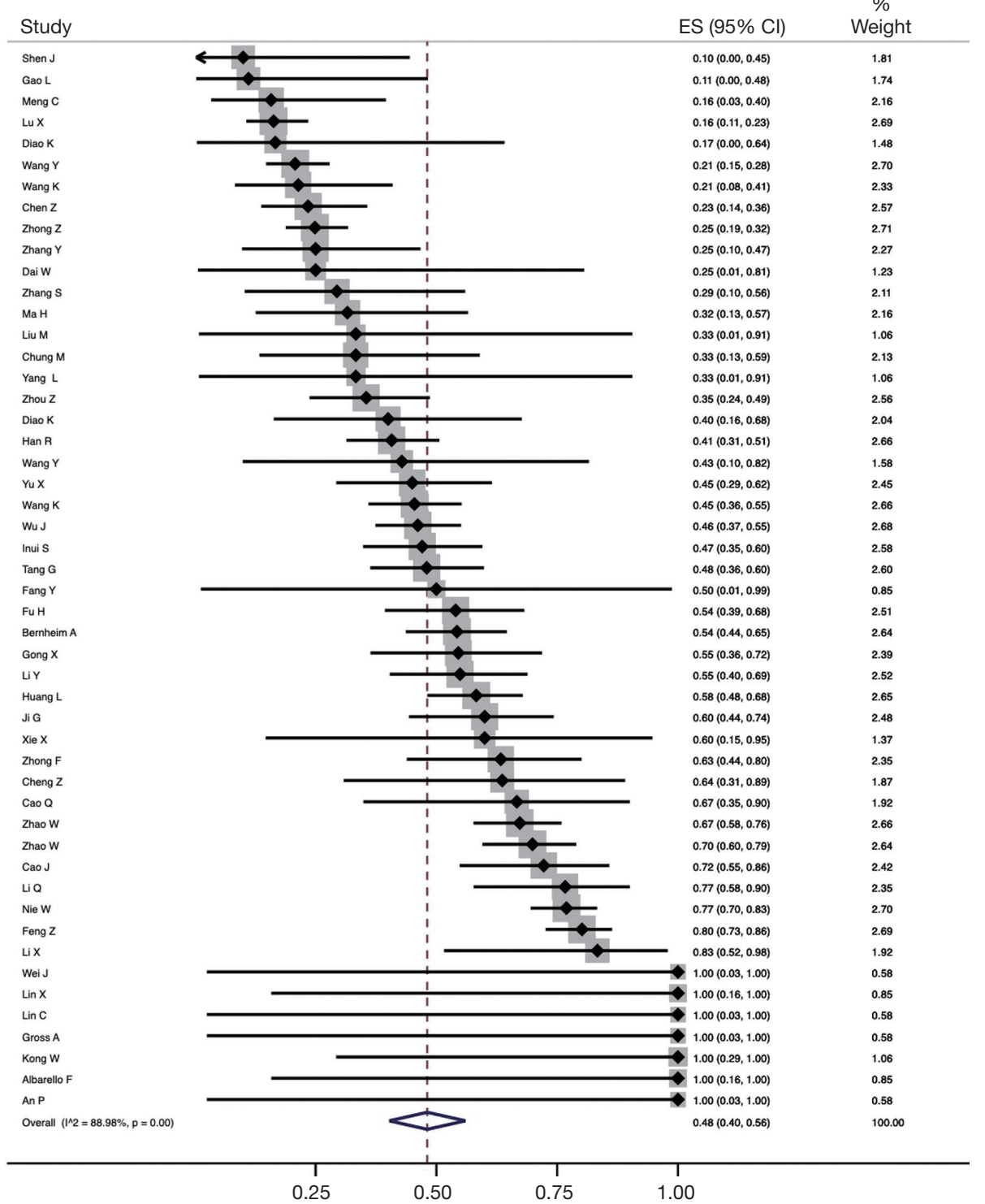

Figure 5 Meta-analyses of probability of lesion density: GGO (A); consolidation (B) and GGO with consolidation (C). GGO, ground-glass opacities. 
Table 1 Meta-analyses of secondary outcomes

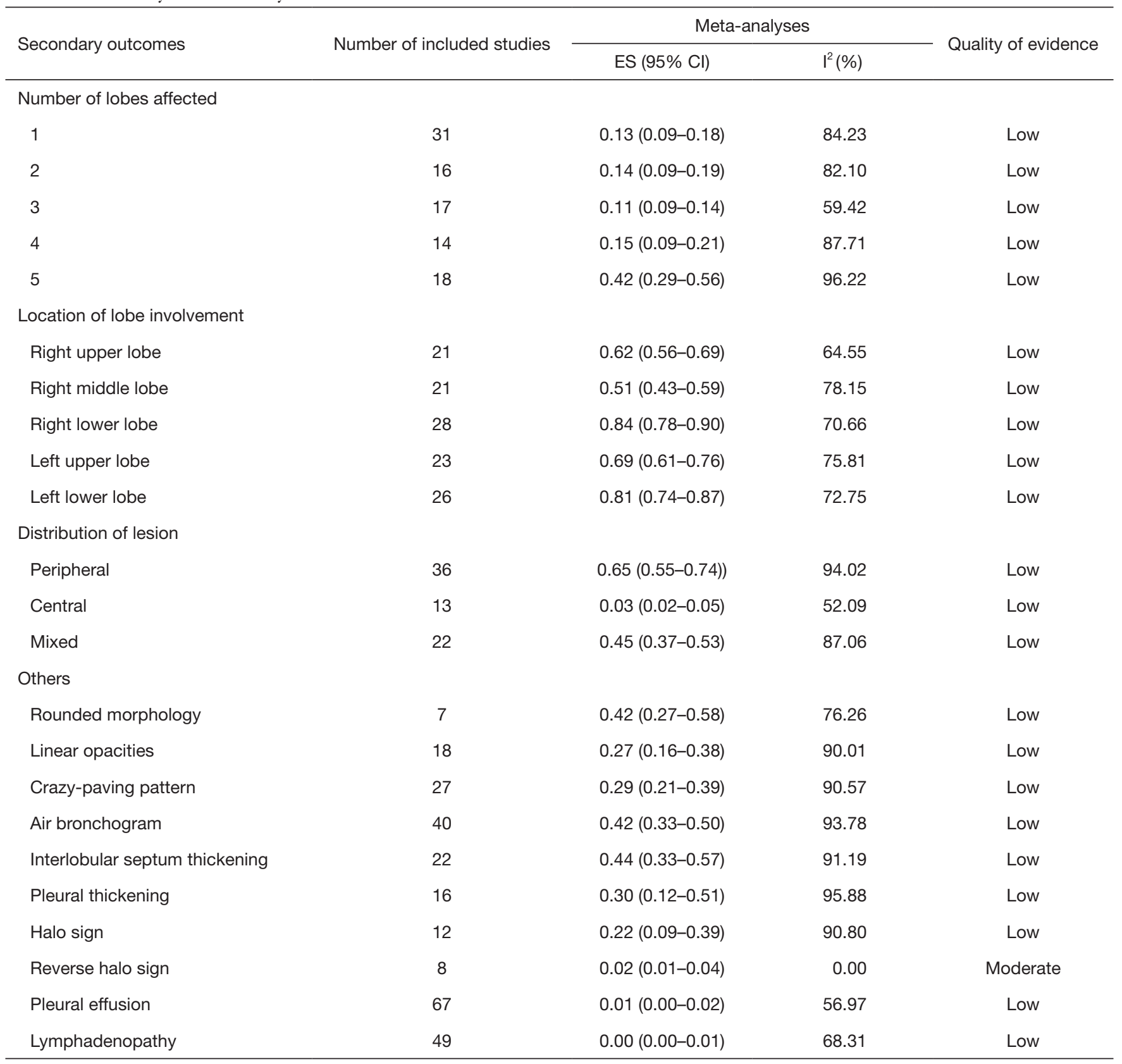

$\mathrm{ES}$, estimated size; $\mathrm{Cl}$, confidence interval.

that using RT-PCR as reference, the sensitivity of chest CT scan in COVID-19 is 99\%, suggesting that CT has the potential to be used as an assisting diagnostic tool. The most common imaging manifestation of patients with COVID-19 is GGO, and the probability of bilateral involvement was $84 \%$. However, the quality of evidence was low across all outcomes. Studies with large sample size and clear reporting are needed in the future to guide the use of CT in the diagnosis and monitoring of patients with COVID-19.

\section{Acknowledgments}

We thank Janne Estill, Institute of Global Health of University of Geneva for providing guidance and comments 
for our review. We thank all the authors for their wonderful collaboration.

Funding: This work was supported by grants from National Clinical Research Center for Child Health and Disorders (Children's Hospital of Chongqing Medical University, Chongqing, China) (grant number NCRCCHD-2020-EP-01) to EL; Special Fund for Key Research and Development Projects in Gansu Province in 2020 to YC; The fourth batch of "Special Project of Science and Technology for Emergency Response to COVID-19" of Chongqing Science and Technology Bureau to EL; Special funding for prevention and control of emergency of COVID-19 from Key Laboratory of Evidence Based Medicine and Knowledge Translation of Gansu Province (grant number No. GSEBMKT-2020YJ01) to YC. The Fundamental Research Funds for the Central Universities (lzujbky-2020-sp14) to YC.

\section{Footnote}

Reporting Checklist: The authors have completed the PRISMA reporting checklist. Available at http://dx.doi. org/10.21037/atm-20-3311

Conflicts of Interest: All authors have completed the ICMJE uniform disclosure form (available at http://dx.doi. org/10.21037/atm-20-3311). MSL serves as the unpaid editorial board member of Annals of Translational Medicine from Nov 2019 to Oct 2021. The other authors have no conflicts of interest to declare.

Ethical Statement: The authors are accountable for all aspects of the work in ensuring that questions related to the accuracy or integrity of any part of the work are appropriately investigated and resolved.

Open Access Statement: This is an Open Access article distributed in accordance with the Creative Commons Attribution-NonCommercial-NoDerivs 4.0 International License (CC BY-NC-ND 4.0), which permits the noncommercial replication and distribution of the article with the strict proviso that no changes or edits are made and the original work is properly cited (including links to both the formal publication through the relevant DOI and the license). See: https://creativecommons.org/licenses/by-nc-nd/4.0/.

\section{References}

1. WHO Director-General's remarks at the media briefing on
2019-nCoV on 11 February 2020[Internet]. World Health Organization; c2020 [cited 2020 Apr 13]. Available online: https://www.who.int/dg/speeches/detail/who-directorgeneral-s-opening-remarks-at-the-media-briefing-oncovid-19---11-march-2020

2. WHO Health Emergency Dashboard. Geneva: WHO; 2020 [Internet]. World Health Organization; 2020 [cited 2020 Apr 12]. Available from: https://who.sprinklr.com/

3. Huang C, Wang Y, Li X, et al. Clinical features of patients infected with 2019 novel coronavirus in Wuhan, China. Lancet 2020;395:497-506.

4. Chen N, Zhou M, Dong X, et al. Epidemiological and clinical characteristics of 99 cases of 2019 novel coronavirus pneumonia in Wuhan, China: a descriptive study. Lancet 2020;395:507-13.

5. Wang D, Hu B, Hu C, et al. Clinical Characteristics of 138 Hospitalized Patients With 2019 Novel CoronavirusInfected Pneumonia in Wuhan, China. JAMA 2020;323:1061-9.

6. Sanche S, Lin YT, Xu C, et al. High Contagiousness and Rapid Spread of Severe Acute Respiratory Syndrome Coronavirus 2. Emerg Infect Dis 2020. [Epub ahead of print]. doi: 10.3201/eid2607.200282.

7. Yang Y, Yang M, Shen C, et al. Laboratory diagnosis and monitoring the viral shedding of 2019-nCoV infections. medRxiv 2020 [cited 2020 April 13]. Available online: https://doi.org/10.1101/2020.02.11.20021493

8. Liao X, Zhou J, Cao J, et al. Comparison of chest CT features between novel coronavirus pneumonia and bacterial pneumonia. Medical Journal of Wuhan University 2020;41:349-52.

9. Yang W, Cheng Z, Cao Q, et al. Clinical Features and Computed Tomographic Manifestations of Patients with 2019 Novel Coronavirus Pneumonia: A Single Center Study in Shanghai, China. SSRN 2020 [cited 2020 Apr 13]. Available online: https://ssrn.com/abstract $=3534223$

10. Chung M, Bernheim A, Mei X, et al. CT imaging features of 2019 novel coronavirus (2019-nCoV). Radiology 2020;295:202-7.

11. Wang $\mathrm{W}, \mathrm{Hu} \mathrm{H}$, Song $\mathrm{L}$, et al. Imaging findings and diagnosis of pneumonia with atypical novel coronavirus (2019-ncov) infection: analysis of 14 cases. New Medicine 2020;30:7-9.

12. Fang $\mathrm{Y}$, Zhang $\mathrm{H}, \mathrm{Xu} \mathrm{Y}$, et al. CT Manifestations of Two Cases of 2019 Novel Coronavirus (2019-nCoV) Pneumonia. Radiology 2020;295:208-9.

13. Wei J, Xu H, Xiong J, et al. 2019 novel coronavirus (COVID-19) pneumonia: serial computed tomography 
findings. Korean Journal of Radiology 2020;21:501-4.

14. Moher D, Liberati A, Tetzlaff J, et al. Preferred reporting items for systematic reviews and meta-analyses: the PRISMA statement. BMJ 2009;339:b2535.

15. Murad MH, Sultan S, Haffar S, et al. Methodological quality and synthesis of case series and case reports. BMJ Evid Based Med 2018;23:60-3.

16. Guyatt GH, Oxman AD, Vist GE, et al; GRADE Working Group. GRADE: an emerging consensus on rating quality of evidence and strength of recommendations. BMJ 2008;336:924-6.

17. Norris SL, Meerpohl JJ, Akl EA, et al. The skills and experience of GRADE methodologists can be assessed with a simple tool. J Clin Epidemiol 2016;79:150-158.e1.

18. Guyatt GH, Oxman AD, Vist GE, et al. GRADE: an emerging consensus on rating quality of evidence and strength of recommendations. BMJ 2008;336:924-6.

19. Guyatt GH, Oxman AD, Montori V, et al. GRADE guidelines: 5 . Rating the quality of evidence-publication bias. J Clin Epidemiol 2011;64:1277-82.

20. Guyatt GH, Oxman AD, Kunz R, et al. GRADE guidelines Rating the quality of evidence-imprecision. J Clin Epidemiol 2011;64:1283-93.

21. Guyatt GH, Oxman AD, Kunz R, et al. GRADE guidelines: 7 . Rating the quality of evidenceinconsistency. J Clin Epidemiol 2011;64:1294-302.

22. Guyatt GH, Oxman AD, Kunz R, et al. GRADE guidelines: 8 . Rating the quality of evidence-indirectness. J Clin Epidemiol 2011;64:1303-10.

23. Xie X, Zhong Z, Zhao W, et al. Chest CT for Typical 2019-nCoV Pneumonia: Relationship to Negative RTPCR Testing. Radiology 2020. [Epub ahead of print].

Cite this article as: $\mathrm{Lv} M$, Wang M, Yang N, Luo X, Li W, Chen X, Liu Y, Ren M, Zhang X, Wang L, Ma Y, Lei J, Fukuoka T, Ahn HS, Lee MS, Luo Z, Chen Y, Liu E, Tian J, Wang X; on behalf of COVID-19 Evidence and Recommendations Working Group. Chest computed tomography for the diagnosis of patients with coronavirus disease 2019 (COVID-19): a rapid review and meta-analysis. Ann Transl Med 2020;8(10):622. doi: 10.21037/atm-20-3311
24. Bernheim A, Mei X, Huang M, et al. Chest CT Findings in Coronavirus Disease-19 (COVID-19): Relationship to Duration of Infection. Radiology 2020. [Epub ahead of print].

25. Ai T, Yang Z, Hou H, et al. Correlation of Chest CT and RT-PCR Testing in Coronavirus Disease 2019 (COVID-19) in China: A Report of 1014 Cases. Radiology 2020. [Epub ahead of print].

26. Fang Y, Zhang H, Xie J, et al. Sensitivity of Chest CT for COVID-19: Comparison to RT-PCR. Radiology 2020;200432. [Epub ahead of print].

27. Qian K, Deng Y, Tai Y, et al. Clinical Characteristics of 2019 Novel Infected Coronavirus Pneumonia: A Systemic Review and Meta-analysis. medRxiv 2020 [cited 2020 Apr 13]. Available online: https://doi. org/10.1101/2020.02.14.20021535

28. Koo HJ, Lim S, Choe J, et al. Radiographic and CT features of viral pneumonia. Radiographics 2018;38:719-39.

29. Wang D, Ju XL, Xie F, et al. Clinical Analysis of 31 Cases of 2019 Novel Coronavirus Infection in Children From Six Provinces (Autonomous Region) of Northern China. Zhonghua Er Ke Za Zhi 2020;58:E269.

30. Zeng LK, Tao XW, Yuan WH, et al. First Case of Neonate Infected With Novel Coronavirus Pneumonia in China. Zhonghua Er Ke Za Zhi 2020;58:E009.

31. Hall EJ. Lessons we have learned from our children: cancer risks from diagnostic radiology. Pediatr Radiol 2002;32:700-6.

32. Mathews JD, Forsythe AV, Brady Z, et al. Cancer risk in 680,000 people exposed to computed tomography scans in childhood or adolescence: data linkage study of 11 million Australians. BMJ 2013;346:f2360. 
Supplementary material 1 Search strategy

PubMed (n=138)

\#1 "COVID-19"[Supplementary Concept]

\#2 "Severe Acute Respiratory Syndrome Coronavirus 2 "[Supplementary Concept]

\#3 "COVID-19"[Title/Abstract]

\#4 "SARS-COV-2"[Title/Abstract]

\#5 "Novel coronavirus"[Title/Abstract]

\#6 "2019-novel coronavirus"[Title/Abstract]

\#7 "coronavirus disease-19"[Title/Abstract]

\#8 "coronavirus disease 2019"[Title/Abstract]

\#9 "COVID19"[Title/Abstract]

\#10 "Novel CoV"[Title/Abstract]

\#11 "2019-nCoV"[Title/Abstract]

\#12 "2019-CoV"[Title/Abstract]

\#13 \#1-\#12/ OR

\#14 "Radiography, Thoracic"[Mesh]

\#15 "computed tomography"[Title/Abstract]

\#16 radiograph*[Title/Abstract]

\#17 imagin*[Title/Abstract]

\#18 \#14-\#17/OR

\#19 \#13 AND \#18

EMBASE $(n=72)$

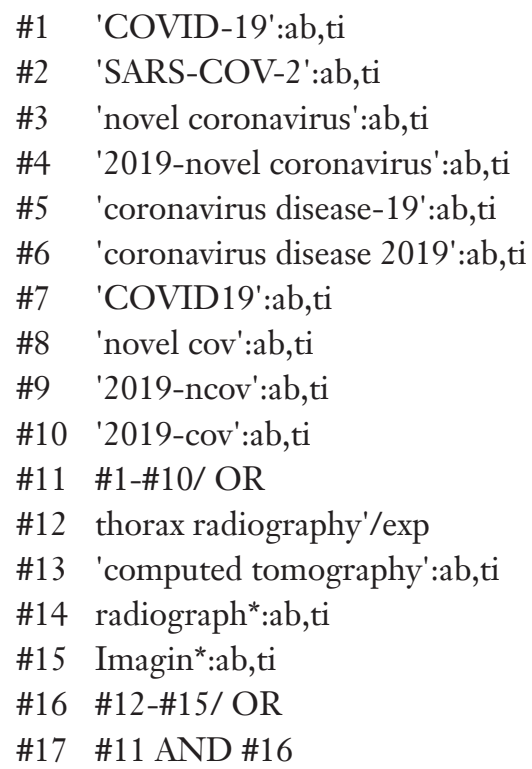

\section{Cochrane Library (n=5)}

\#1 "COVID-19":ti,ab,kw

\#2 "SARS-COV-2":ti,ab,kw
\#3 "Novel coronavirus":ti,ab,kw

\#4 "2019-novel coronavirus" :ti,ab,kw

\#5 "Novel CoV" :ti,ab,kw

\#6 "2019-nCoV" :ti,ab,kw

\#7 "2019-CoV" :ti,ab,kw

\#8 "coronavirus disease-19" :ti,ab,kw

\#9 "coronavirus disease 2019" :ti,ab,kw

\#10 "COVID19" :ti,ab,kw

\#11 \#1-\#10/ OR

\#12 MeSH descriptor: [Radiography, Thoracic] explode all trees

\#13 "computed tomography":ti,ab,kw

\#14 radiograph*:ti,ab,kw

\#15 imagin*:ti,ab,kw

\#16 \#12-\#15/ OR

\#17 \#11 AND \#16

Web of Science $(n=27)$

\#1 TOPIC: "COVID-19"

\#2 TOPIC: "SARS-COV-2"

\#3 TOPIC: "Novel coronavirus"

\#4 TOPIC: "2019-novel coronavirus"

\#5 TOPIC: "coronavirus disease-19" [Title/Abstract]

\#6 TOPIC: "coronavirus disease 2019" [Title/Abstract]

\#7 TOPIC: "COVID19" [Title/Abstract]

\#8 TOPIC: "Novel CoV"

\#9 TOPIC: "2019-nCoV"

\#10 TOPIC: "2019-CoV"

\#11 \#1-\#10/ OR

\#12 TOPIC: "computed tomography"

\#13 TOPIC: "radiograph*"

\#14 TOPIC: "imagin*"

\#15 "computed tomography"[Title/Abstract]

\#16 radiograph*[Title/Abstract]

\#17 imagin*[Title/Abstract]

\#18 \#12-\#17/ OR

\#19 \#11 AND \#18 
\#8“CT 扫描”[ 主题 ]

\#9“CAT 扫描”[ 主题 ]

\#10 “电子束计算机断层摄影术” [ 主题 ]

\#11 “断层摄影术”[主题 ]

\#12 “计算机断层摄影术”[ 主题 ]

\#13 \#8-\#12/ OR

\#14 \#7 AND \#13

\section{$C B M(n=163)$}

\#1 “新型冠状病毒” [ 常用字段 : 智能 ]

\#2 “2019-nCoV”[ 常用字段: 智能]

\#3 “2019-CoV”[ 常用字段 : 智能 ]

\#4 “COVID-19”[ 常用字段 : 智能 ]

\#5“COVID 19”[ [ 常用字段: 智能 ]

\#6 “SARS-CoV-2”[ 常用字段 : 智能 ]

\#7 \#1-\#6/ OR

\#8 “CT 扫描”[ 常用字段 : 智能 ]

\#9“CAT 扫描”[ 常用字段 : 智能 ]

\#10 “电子束计算机断层摄影术” [ 常用字段 : 智能 ]

\#11 “断层摄影术”[ 常用字段 : 智能 ]
\#12 “计算机断层摄影术” [ 常用字段 : 智能 ]

\#13 \#8-\#12/ OR

\#14 \#7 AND \#13

\section{WangFang ( $n=36)$}

\#1 “新型冠状病毒” [ 主题 ]

\#2 “2019-nCoV”[ 主题]

\#3 “2019-CoV”[主题]

\#4 “COVID-19”[主题 ]

\#5 “COVID 19”[ 主题]

\#6 “SARS-CoV-2”[ 主题]

\#7 \#1-\#6/ OR

\#8“CT 扫描”[ 主题 ]

\#9 “CAT 扫描” [主题 ]

\#10 “电子束计算机断层摄影术” [ 主题 ]

\#11 “断层摄影术”[主题]

\#12 “计算机断层摄影术”[ 主题 ]

\#13 \#8-\#12/ OR

\#14 \#7 AND \#13 


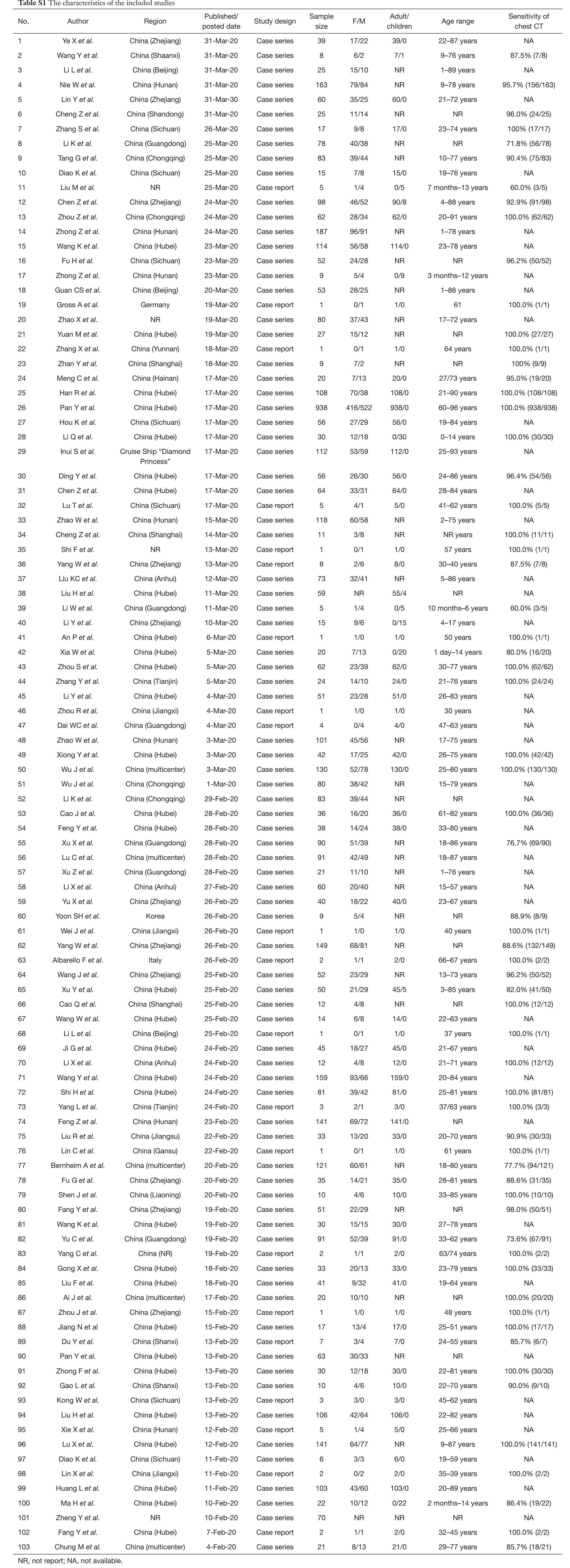




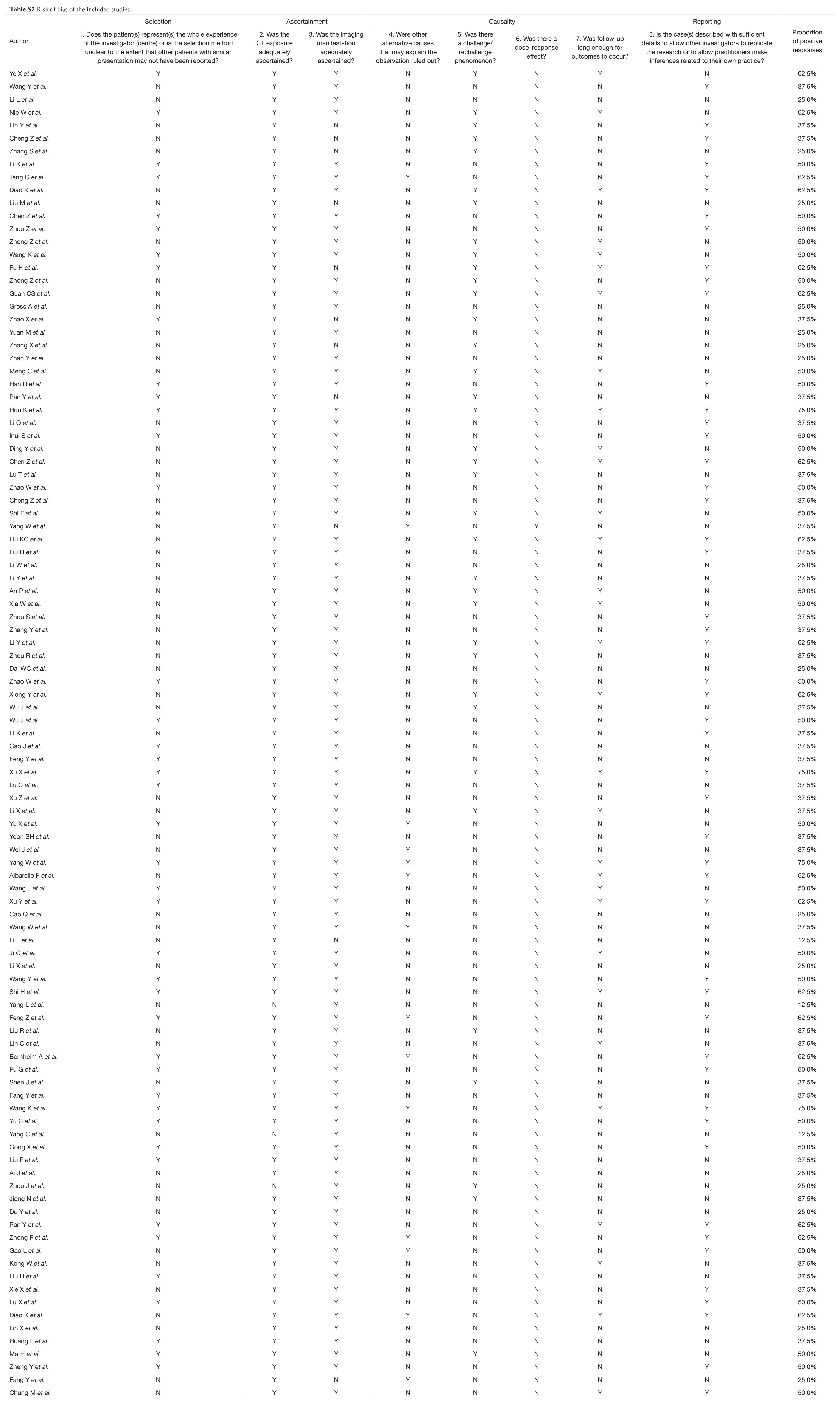




\section{Supplementary material 2 List of included studies}

1. Ye X, Xie Y, Xu C, et al. Clinical features, CT manifestations and dynamic changes of corona virus disease 2019. Journal of Wenzhou Medical University 2020:1-11. doi: 10.3969/j.issn.2095-9400.2020.03.003.

2. Wang $\mathrm{Y}$, Kong $\mathrm{Y}, \mathrm{Yu} \mathrm{W}$, et al. Laboratory examination and CT features of family aggregative corona virus disease 2019 patients at first visit. Shaanxi Medical Journal 2020;49:392-6.

3. Li L, Wang K, Ren M, et al. Early chest CT manifestations of COVID-19. Journal of Capital Medical University 2020;41:1-4.

4. Nie W, Feng Z, Mao X, et al. First CT characteristic appearance of patients with coronavirus disease 2019. Journal of Central South University (Medical Science) 2020;45:262-8.

5. Lin Y, Chen L, Li Y, et al. CT appearances and dynamic changes in coronavirus disease 2019. Journal of Wenzhou Medical University 2020:1-10. doi: 10.3969/ j.issn.2095-9400.2020.04.002

6. Cheng Z, Li Y, Duan Y, et al. A preliminary study on the dynamic image evolution of chest high resolution CT in patients with mild COVID-19. Chin J Radiol 2020;54. [Epub ahead of print].

7. Zhang S, Li H, Huang S, et al. High-resolution computed tomography features of 17 cases of coronavirus disease 2019 in Sichuan province, China. Eur Respir J 2020;55:2000334.

8. Li K, Fang Y, Li W, et al. CT image visual quantitative evaluation and clinical classification of coronavirus disease (COVID-19). Eur Radiol 2020;1-10. [Epub ahead of print].

9. Tang G, Li C, Liu X, et al. Clinical and CT findings of coronavirus disease 2019. Chinese Journal of Respiratory and Critical Care Medicine 2020;19:161-5.

10. Diao K, Han P, Pang T, et al. The features and longitudinal changes on high-resolution computed tomography for patients with coronavirus disease 2019. Chinese Journal of Respiratory and Critical Care Medicine $2020 ; 166-71$.

11. Liu M, Song Z, Xiao K. High-Resolution Computed Tomography Manifestations of 5 Pediatric Patients With 2019 Novel Coronavirus. J Comput Assist Tomogr 2020. [Epub ahead of print].

12. Chen Z, Fan H, Cai J, et al. High-resolution computed tomography manifestations of COVID-19 infections in patients of different ages. Eur J Radiol 2020;126:108972.

13. Zhou Z, Guo D, Li C, et al. Coronavirus disease 2019: initial chest CT findings. Eur Radiol 2020;1-9. [Epub ahead of print].

14. Zhong Z, Hu Y, Yu Q, et al. Multistage CT features of coronavirus disease 2019. Journal of Central South University (Medical Science) 2020;45:250-6.

15. Wang K, Kang S, Tian R, et al. Imaging manifestations and diagnostic value of chest $\mathrm{CT}$ of coronavirus disease 2019 (COVID-19) in the Xiaogan area. Clin Radiol 2020;75:341-7.

16. $\mathrm{Fu} \mathrm{H}, \mathrm{Xu} \mathrm{H}$, Zhang N, et al. Association between Clinical Laboratory and CT Characteristics and RT-PCR Results in the Follow-up of COVID-19 patients. medRxiv 2020. doi: https://doi.org/10.1101/2020.03.19.20038315.

17. Zhong Z, Xie X, Huang W, et al. Chest CT findings and clinical features of coronavirus disease 2019 in children. Journal of Central South University (Medical Science) 2020;45:236-42.

18. Guan CS, Lv ZB, Yan S, et al. Imaging Features of Coronavirus disease 2019 (COVID-19): Evaluation on Thin-Section CT. Acad Radiol 2020;27:609-13.

19. Gross A, Thiemig D, Koch FW, et al. CT appearance of severe, laboratory-proven coronavirus disease 2019 (COVID-19) in a Caucasian patient in Berlin, Germany. Rofo 2020;192:476-7.

20. Zhao X, Liu B, Yu Y, et al. The characteristics and clinical value of chest $\mathrm{CT}$ images of novel coronavirus pneumonia. Clinical Radiology 2020;75:335-40.

21. Yuan $M$, Yin W, Tao Z, et al. Association of radiologic findings with mortality of patients infected with 2019 novel coronavirus in Wuhan, China. PLoS One 2020;15:e230548.

22. Zhang X, Song W, Liu X, et al. CT image of novel coronavirus pneumonia: a case report. Jpn J Radiol 2020;38:407-8.

23. Zhan Y, Liu H, Li K. Preliminary Finding of SARSCoV-2 Infection: Clinical and Chest CT Features. Chinese Computed Medical Imaging 2020. doi: 10.19627/j.cnki. cn31-1700/th.20200316.001.

24. Meng C, Chen Y, Liu K. CT features of COVID-2019: a study of 20. Gongdong Medicine Journal, 2020. doi: 10.13820/j.cnki.gdyx.20200697.

25. Han R, Huang L, Jiang H, et al. Early Clinical and CT Manifestations of Coronavirus Disease 2019 (COVID-19) Pneumonia. AJR Am J Roentgenol 2020:1-6. [Epub ahead of print].

26. Pan Y, Wang Y, Zhu T, et al. CT features of 938 senile patients with corona virus disease 2019 pneumonia. Radiologic Practice 2020;35:269-71.

27. Hou K, Zhang N, Lee T, et al. CT features of corona 
virus disease 2019 (COVID-19) in different stages and its correlation with neutrophil-lymphocyte ratio (NLR) and T lymphocyte subsets. Radiologic Practice 2020;35:272-6.

28. Li Q, Peng X, Sun Z, et al. Clinical and imaging characteristics of children with corona virus disease 2019 (COVID-19). Radiologic Practice 2020;35:277-80.

29. Inui S, Fujikawa A, Jitsu M, et al. Chest CT findings in cases from the cruise ship "Diamond Princess" with coronavirus disease 2019 (COVID-19). Radiology: Cardiothoracic Imaging 2020;2:e200110.

30. Ding $Y$, Huang $Z$, Zhao $S$, et al. Clinical and imaging characteristics of corona virus disease 2019 (COVID-19). Radiologic Practice 2020;35:281-5.

31. Chen Z, Li Z, Zhang X, et al. Clinical manifestations and CT characteristics of corona virus disease 2019 (COVID-19). Radiologic Practice 2020;35:286-90.

32. Lu T, Pu H. Computed Tomography Manifestations of 5 Cases of the Novel Coronavirus Disease 2019 (COVID-19) Pneumonia From Patients Outside Wuhan. J Thorac Imaging 2020;35:W90-W93.

33. Zhao W, Zhong Z, Xie X, et al. CT Scans of Patients with 2019 Novel Coronavirus (COVID-19) Pneumonia. Theranostics 2020;10:4606-13.

34. Cheng Z, Lu Y, Cao Q, et al. Clinical Features and Chest CT Manifestations of Coronavirus Disease 2019 (COVID-19) in a Single-Center Study in Shanghai, China. AJR Am J Roentgenol 2020:1-6. [Epub ahead of print].

35. Shi F, Yu Q, Huang W, et al. 2019 Novel Coronavirus (COVID-19) Pneumonia with Hemoptysis as the Initial Symptom: CT and Clinical Features. Korean J Radiol 2020;21:537-40.

36. Yang $\mathrm{W}$, Weng $\mathrm{Q}$, Xiao $\mathrm{Y}$, et al. CT findings and clinical features of COVID-19 in 8 patients with foreign imported cluster disease. Chinese Journal of Radiology 2020. doi: 10.3760/cma.j.cn112149-20200306-00333.

37. Liu KC, Xu P, Lv WF, et al. CT manifestations of coronavirus disease-2019: A retrospective analysis of 73 cases by disease severity. Eur J Radiol 2020;126:108941.

38. Liu H, Liu F, Li J, et al. Clinical and CT imaging features of the COVID-19 pneumonia: Focus on pregnant women and children. J Infect 2020;80:e7-e13.

39. Li W, Cui H, Li K, et al. Chest computed tomography in children with COVID-19 respiratory infection. Pediatr Radiol 2020:1-4. [Epub ahead of print].

40. Li Y, Ye Y, Xuan W, et al. Imaging features of the initial chest high resolution CT scan in juvenile patient with Coronavirus disease 2019. Chin J Gen Pract 2020;19. [Epub ahead of print].

41. An P, Song P, Lian K, et al. CT Manifestations of Novel
Coronavirus Pneumonia: A Case Report. Balkan Med J 2020;37:163-5.

42. Xia W, Shao J, Guo Y, et al. Clinical and CT features in pediatric patients with COVID-19 infection: Different points from adults. Pediatr Pulmonol 2020;55:1169-74.

43. Zhou S, Wang Y, Zhu T, et al. CT Features of Coronavirus Disease 2019 (COVID-19) Pneumonia in 62 Patients in Wuhan, China. AJR Am J Roentgenol 2020:1-8. [Epub ahead of print].

44. Zhang Y, Li W, Gao W, et al. Thin-Section CT features in adult patients with novel coronavirus pneumonia. Shandong Medical Journal 2020;60:86-9.

45. Li Y, Xia L. Coronavirus Disease 2019 (COVID-19): Role of Chest CT in Diagnosis and Management. AJR Am J Roentgenol 2020:1-7. [Epub ahead of print].

46. Zhou R, Chen Y, Lin C, et al. Asymptomatic COVID-19 in pregnant woman with typical chest CT manifestation: a case report. Chinese Journal of Perinatal Medicine 2020;23. [Epub ahead of print].

47. Dai WC, Zhang HW, Yu J, et al. CT Imaging and Differential Diagnosis of COVID-19. Can Assoc Radiol J 2020;71:195-200.

48. Zhao W, Zhong Z, Xie X, et al. Relation Between Chest CT Findings and Clinical Conditions of Coronavirus Disease (COVID-19) Pneumonia: A Multicenter Study. AJR Am J Roentgenol 2020;214:1072-7.

49. Xiong Y, Sun D, Liu Y, et al. Clinical and High-Resolution CT Features of the COVID-19 Infection: Comparison of the Initial and Follow-up Changes. Invest Radiol 2020;55:332-9.

50. Wu J, Feng C, Xian X, et al. Novel coronavirus pneumonia (COVID-19) CT distribution and sign features. Chin J Tuberc Respir Dis 2020;43. [Epub ahead of print].

51. Wu J, Wu X, Zeng W, et al. Chest CT Findings in Patients With Coronavirus Disease 2019 and Its Relationship With Clinical Features. Invest Radiol 2020;55:257-61.

52. Li K, Wu J, Wu F, et al. The Clinical and Chest CT Features Associated With Severe and Critical COVID-19 Pneumonia. Invest Radiol 2020;55:327-31.

53. Cao J, Zhou J, Liao X, et al. Clinical features and CT findings of elderly patients with novel coronavirus pneumonia. Medical Journal of Wuhan University 2020. doi: 10.14188/j.1671-8852.2020.0087

54. Feng Y, Yuan L, Zheng C, et al. Practical application of $\mathrm{CT}$ and nucleic acid detection in the diagnosis of COVID-19. Guangdong Medical Journal 2020;41:440-3.

55. Xu X, Yu C, Qu J, et al. Imaging and clinical features of patients with 2019 novel coronavirus SARS-CoV-2. Eur J Nucl Med Mol Imaging 2020;47:1275-80. 
56. Lu C, Yang W, Hu Y, et al. Coronavirus Disease 2019 (COVID-19) Pneumonia: Early Stage Chest CT Imaging Features and Clinical Relevance. SSRN 2020. [cited 2020 Apr 13]. Available online: https://papers.ssrn.com/sol3/ papers.cfm?abstract_id $=3543606$

57. Xu Z, Wu W, Jin YB, et al. Key Points of Clinical and CT Imaging Features of 2019 Novel Coronavirus (2019-nCoV) Imported Pneumonia Based On 21 Cases Analysis. 2020. Available at SSRN: https://ssrn.com/abstract $=3543610$ or http://dx.doi.org/10.2139/ssrn.3543610

58. Li X, Wang H, Zhu J, et al. Imaging dynamic observation of COVID-19 patients cured by imported coronavirus pneumonia. Chinese Journal of Radiology 2020;54. [Epub ahead of print].

59. Yu X, Ye H, Yang S, et al. Chest CT features of COVID-19. The Journal of Practical Medicine 2020. [Epub ahead of print]. Available online: http://kns.cnki. net/kcms/detail/44.1193.R.20200225.1621.002.html

60. Yoon SH, Lee KH, Kim JY, et al. Chest Radiographic and CT Findings of the 2019 Novel Coronavirus Disease (COVID-19): Analysis of Nine Patients Treated in Korea. Korean J Radiol 2020;21:494-500.

61. Wei J, Xu H, Xiong J, et al. 2019 Novel Coronavirus (COVID-19) Pneumonia: Serial Computed Tomography Findings. Korean J Radiol 2020;21:501-4.

62. Yang W, Cao Q, Qin L, et al. Clinical characteristics and imaging manifestations of the 2019 novel coronavirus disease (COVID-19): A multi-center study in Wenzhou city, Zhejiang, China. J Infect 2020;80:388-93.

63. Albarello F, Pianura E, Di Stefano F, et al. 2019-novel Coronavirus severe adult respiratory distress syndrome in two cases in Italy: An uncommon radiological presentation. Int J Infect Dis 2020;93:192-7.

64. Wang J, Liu J, Wang Y, et al. Dynamic changes of chest CT imaging in patients with corona virus disease-19 (COVID-19). Journal of Zhejiang University (Medical Science) 2020;49. doi: 10.3785/ j.issn.1008-9292.2020.02.03.

65. Xu Y, Dong J, An W, et al. Clinical and computed tomographic imaging features of Novel Coronavirus Pneumonia caused by SARS-CoV-2. Journal of Infection 2020;80:394-400.

66. Cao Q, Qin Y, Zhou H, et al. CT features of 2019 novel coronavirus pneumonia. J Diagn Concepts Pract 2020;19:16-9.

67. Wang $\mathrm{W}, \mathrm{Hu} \mathrm{H}$, Song L, et al. Image of pulmonary and diagnosis of atypical novel coronavirus (2019-nCoV) infected pneumonia: case series of 14 patients. New Medicine 2020;30:7-9.
68. Li L, Ren M, Zhang Y, et al. Lung CT image of a confirmed case of the 2019 novel coronavirus (2019-nCoV) infected pneumonia (With differential diagnosis of the SARS). New Medicine 2020;30:4-6.

69. Ji G, Huang $M$, Zhang Q, et al. CT manifestations and dynamic changes of corona virus disease 2019. Chin J Med Imaging Technol 2020;36:242-7

70. Li X, Pan H, Shu J, et al. Clinical and CT features of Imported COVID-19. Chin J Med Imaging Technol 2020;36:248-51.

71. Wang Y, Chen J, Wang X, et al. CT imaging analysis of COVID-19 asymptomatic patients. Medical Journal of Wuhan University 2020;41:353-6.

72. Shi H, Han X, Jiang N, et al. Radiological findings from 81 patients with COVID-19 pneumonia in Wuhan, China: a descriptive study. Lancet Infect Dis 2020;20:425-34.

73. Yang $\mathrm{L}, \mathrm{Li} \mathrm{W}, \mathrm{Hao} \mathrm{W}$, et al. CT manifestations of aggregative corona virus disease 2019: Three cases report. Chin J Med Imaging Technol 2020;36:314-5.

74. Feng Z, Yu Q, Yao S, et al. Early Prediction of Disease Progression in 2019 Novel Coronavirus Pneumonia Patients Outside Wuhan with CT and Clinical Characteristics. medRxiv 2020 [cited 2020 Apr 13]. Available online: https://www.medrxiv.org/content/10.110 1/2020.02.19.20025296v1

75. Liu RR, Zhu Y, Wu MY, et al. CT imaging analysis of 33 cases with the 2019 Novel coronavirus infection. Zhonghua Yi Xue Za Zhi 2020;100:1007-11.

76. Lin C, Ding Y, Xie B, et al. Asymptomatic novel coronavirus pneumonia patient outside Wuhan: The value of CT images in the course of the disease. Clin Imaging 2020;63:7-9.

77. Bernheim A, Mei X, Huang M, et al. Chest CT Findings in Coronavirus Disease-19 (COVID-19): Relationship to Duration of Infection. Radiology. 2020;200463. [Epub ahead of print].

78. Fu G, Xu C, Sun H, et al. Application of chest CT examination in screening patients with novel coronavirus pneumonia. Journal of Wenzhou Medical University 2020. Available online: http://kns.cnki.net/kcms/detail/33.1386. r.20200219.1451.002.html

79. Shen J, Yu J, Yan Y, et al. Clinical and chest HRCT characteristics in family group outbreak of novel coronavirus pneumonia. Journal of Dalian Medical University 2020;42:32-6.

80. Fang Y, Zhang H, Xie J, et al. Sensitivity of Chest CT for COVID-19: Comparison to RT-PCR. Radiology 2020. [Epub ahead of print].

81. Wang K, Kang S, Tian R, et al. CT characteristic 
appearances of patients with novel coronavirus pneumonia. Chinese Journal of Clinical Medicine 2020. Available online: http://kns.cnki.net/kcms/detail/31.1794. R.20200217.1344.004.html

82. Yu C, Qu J, Zhang L, et al. High resolution CT findings and clinical features of COVID - 19 in Guangzhou area. Chinese Journal of Radiology 2020;54:314-7.

83. Yang C, Fan C, Cheng A, et al. CT features of 2019-novel coronovirus pneumonia: SARS and MERS literature review and analysis of CT features of two confirmed 2019-novel coronavirus pneumonia cases. Chin Crit Care Med 2020;2:1-3.

84. Gong X, Li H, Song L, et al. Preliminary study on CT findings of novel coronavirus pneumonia (COVID-19). Radiologic Practice 2020;35:260.

85. Liu F, Ding H, Gong X, et al. Chest CT findings and clinical features of novel coronavirus pneumonia (COVID-19). Radiologic Practice. 2020-03-14]. doi: 10.13609/j.cnki.1000-0313.2020.03.004

86. Ai J, Zhang H, Xu T, et al. Optimizing diagnostic strategy for novel coronavirus pneumonia, a multi-center study in Eastern China. medRxiv 2020 [cited 2020 Apr 13]. Available online: https://www.medrxiv.org/content/10.110 $1 / 2020.02 .13 .20022673 \mathrm{v} 1$.

87. Zhou J, Zhang D, Chen H, et al. Atypical chest CT in corona virus disease: A case report and literature review. Chin J Clin Infect Dis 2020;13. [Epub ahead of print].

88. Jiang N, Zheng C, Fan Y, et al. Characteristics and shortterm evolution of COVID-19 subclinical CT imaging. Chinese Journal of Radiology 2020;54:305-9.

89. Du Y, Jin C, Yang J, et al. Preliminary study on the clinical and CT findings of early family aggregation pneumonia with novel coronavirus. Journal of Xi'an Jiaotong University (Medical Sciences) 2020. Available online: http://kns.cnki.net/kcms/detail/61.1399. r.20200213.0838.004.html

90. Pan Y, Guan H, Zhou S, et al. Initial CT findings and temporal changes in patients with the novel coronavirus pneumonia (2019-nCoV): a study of 63 patients in Wuhan, China. Eur Radiol 2020. [Epub ahead of print].

91. Zhong F, Zhang H, Wang B, et al. CT findings in 2019 novel coronavirus disease (COVID-19) patients. Medical
Journal of Wuhan University 2020,41:345-8.

92. Gao L, Zhang J, Du Y, et al. CT findings of imported novel coronavirus pneumonia. Journal of Xi'an Jiaotong University (Medical Sciences) Available online: http://kns. cnki.net/kcms/detail/61.1399.r.20200213.1259.009.html

93. Kong W, Agarwal PP. Chest imaging appearance of COVID-19 infection. Radiology: Cardiothoracic Imaging 2020;2:e200028.

94. Liu H, Zhang D, Yang Y, et al. Analysis of the initial chest high resolution CT manifestations of COVID-19. Chin J Radiol 2020;54: 292-5.

95. Xie X, Zhong Z, Zhao W, et al. Chest CT for Typical 2019-nCoV Pneumonia: Relationship to Negative RTPCR Testing. Radiology 2020;200343. [Epub ahead of print].

96. Lu X, Gong W, Wang L, et al. The clinical features of new coronavirus pneumonia and its high-resolution CT image. Chinese Journal of Radiology 2020;54:296.

97. Diao K, Han P, Pang T, et al. HRCT imaging features in representative imported cases of 2019 novel coronavirus pneumonia. Precision Clinical Medicine 2020;3:9-13.

98. Lin X, Gong Z, Xiao Z, et al. Novel Coronavirus Pneumonia Outbreak in 2019: Computed Tomographic Findings in Two Cases. Korean J Radiol 2020;21:365-8.

99. Huang L, Han R, Yu P, et al. A correlation study of CT and clinical features of different clinical types of COVID-19. Chin J Radiol 2020,54:300-4.

100.Ma H, Shao J, Wang Y, et al. High resolution CT features of novel coronavirus pneumonia in children. Chinese Journal of Radiology 2020;54. doi: 10.3760/cma. j.cn112149-20200206-00100.

101.Zheng Y, Ma X, Wang H, et al. CT findings of a new type of coronavirus pneumonia. Shanghai Medical Journal 2020. Available online: http://kns.cnki.net/kcms/ detail/31.1366.r.20200209.1042.002.html

102. Fang Y, Zhang H, Xu Y, et al. CT manifestations of two cases of 2019 novel coronavirus (2019-nCoV) pneumonia. Radiology 2020;295:208-9.

103. Chung M, Bernheim A, Mei X, et al. CT imaging features of 2019 novel coronavirus (2019-nCoV). Radiology 2020;295:202-7. 